\title{
The Return of Craft Designer (Pattern Maker) Re-Valued Through the New 3D Technologies
}

\author{
Jean-Marc SURVILLE, Lectra, Cestas, France
}

\begin{abstract}
The 3D context has taken a wide field of interest: Avatars generation, from scanning real people to virtual avatars for games. Today real bodies are used in kinect ${ }^{\mathrm{TM}}$ world for consuming (self esteem). However the virtual space between scan bodies and avatars to virtual shopping opens various opportunities. The virtual world, even built on expert systems skill, get added values to the target users, within the apparel industry an undeniable support for designers and pattern makers daily works and decisions. Mannequin, garment (style) and fabric: here is the trilogy at the heart of the designers' decision step. These profiles, supposed to be outperformed by these technical realization, become now the most representative users because of the discover of new tools supporting their creative activities.
\end{abstract}

Keywords: virtual try-on, apparel skill, pattern maker.

\section{Introduction}

We are living a period where the industry suffer from the general crisis status. However in this period consumers go back to the "hand sewn" concept. Thanks to the net activity, a new generation enhance the fundamental concepts for fashion.(1). At the same time, the high technology foe 3D representation, invade video games, the CAD professional space, flight simulator home staging, etc...

The sill knowledge embedded through expert systems offer a real computer assisted design. This kind of tool was originally dedicated to engineers. CAD may contain different level of embedded knowledge. These knowledge may be embedded in different products. The online access as well as smart phones let the technologies directly accessible to consumers.

Is there any more place for the designers ideas?

\section{CAD in apparel industry}

Cad systems entered into the market at the beginning of the 80's. Lectra, Hugues, Gerber (2). At the very heart of $2 \mathrm{D}$ patterns mostly used as production templates, the modification and grading occurred introducing pattern construction through a screen. (3). Now the skill is well introduced using the 2D Cad systems.

However the representation in 3D of people wearing garments was driven by games (maya cloth) as well as catwalks evocation (4).

Realistic simulation including a mechanical model of fabric behavior appear with the Xavier Provot works at INRIA (5).

Different models for fabric mechanical representation were proposed. Finite element an mass spring. Anyhow all were supposed to integrate the most important fabric effects such as density, elasticity bending and some hysteresis (6). 

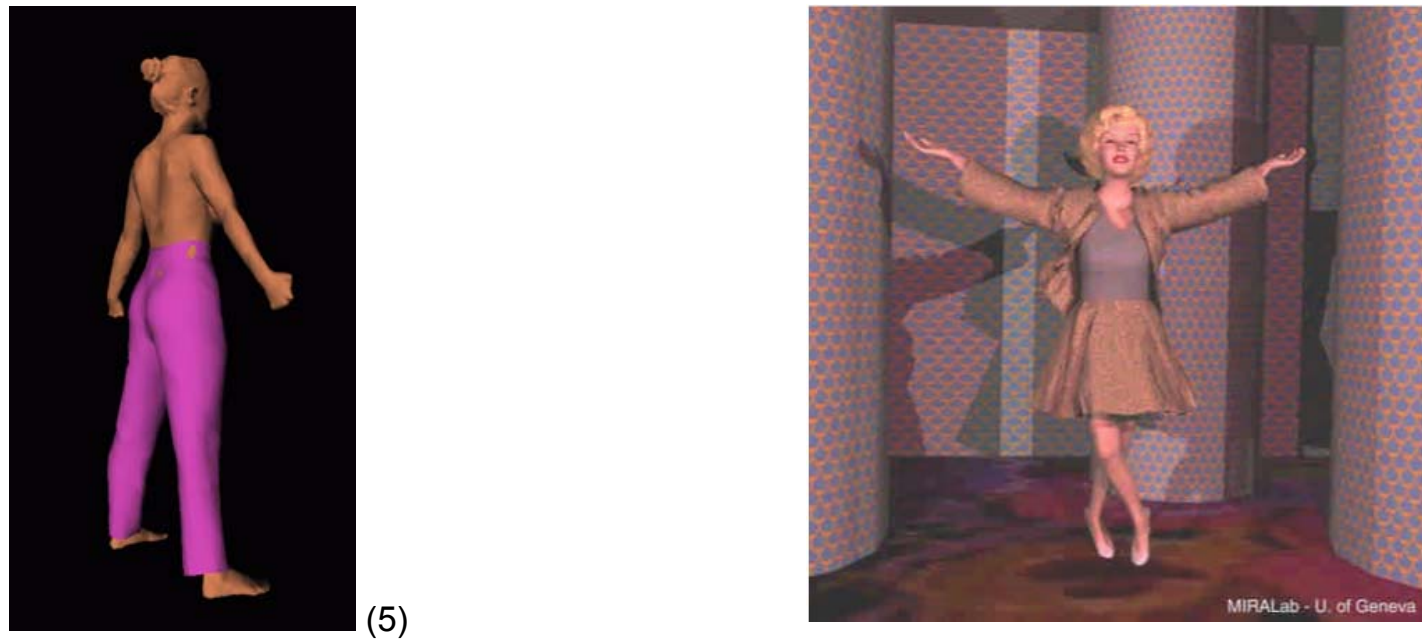

(4)

Real bodies were used for the first simulation of $X$. Provot, from the Cyberwear scans.

Now the place of 3D simulation is at the heart of many research done by universities (6).

\section{The 3D invasion}

Artificial mannequins as poser digital artists (7), have given a new context for virtual world and representation. However this does not concern the everyday common consuming such as apparel shopping.
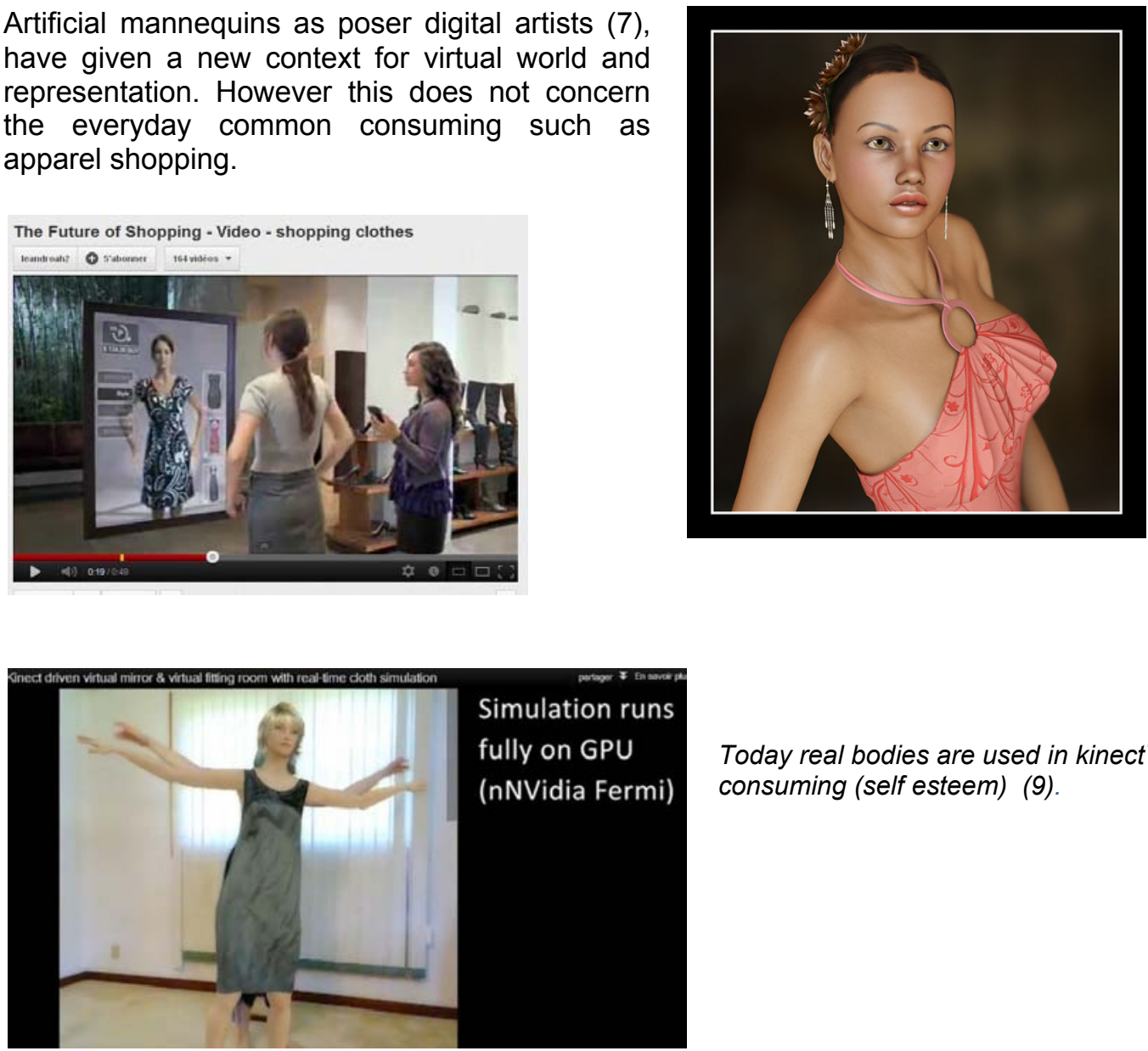

Today real bodies are used in kinect ${ }^{\mathrm{TM}}$ world for consuming (self esteem) (9). 


\section{a. Apparel industriy tools}

2D pattern design have taken a wide place in garment industry :Expert systems may influence the creativity

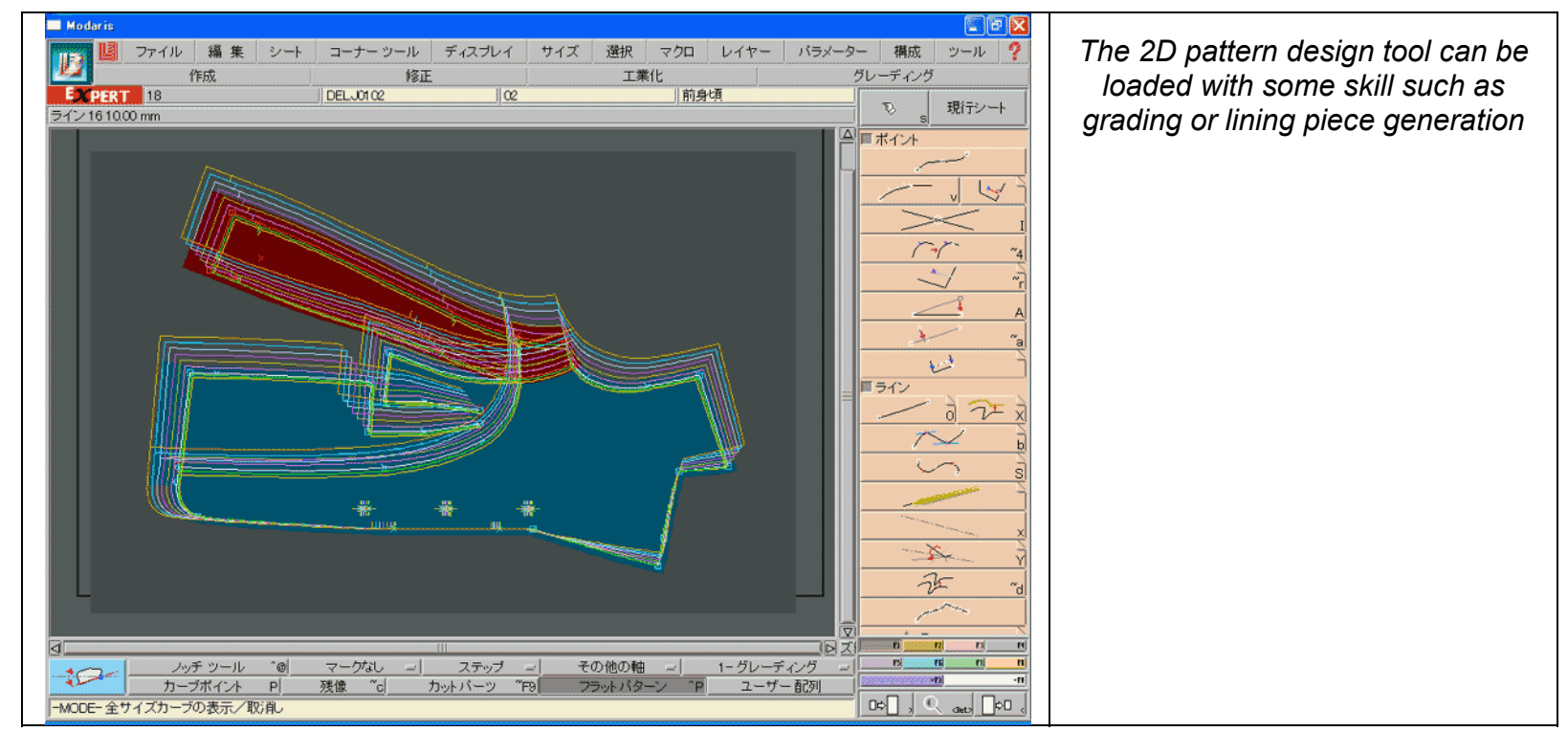

\section{b. Experts imbedded}

The virtual world, even built on expert systems skill, get added values to the target users, within the apparel industry an undeniable support for designers and pattern makers daily works and decisions.

Now do the expert systems will reduce the skilled professional to simple operators?

See papers dealing with all aspects of knowledge engineering, including individual methods and techniques in knowledge acquisition and representation, their application and evaluation, and the construction of systems.(11)

Even if artificial intelligence can build decisions in place of humans, in a field such as apparel fashion, irrational expectations may take a great place as a matter of emotion.

However, the interest for production control reproducibility of process and reliability remains obvious.

\section{c. The $3^{\text {rd }}$ dimension as a technology}

The virtual space between scan bodies and avatars to virtual shopping opens various opportunities

The introduction of the $3^{\text {rd }}$ dimension as a technology has become a real cultural transformation as a matter of appreciation of creation mostly in fashion world. 


\section{The trilogy. In apparel industry}

Garment (style), mannequin, and fabric: here is the trilogy at the heart of the designers' decision step (13)

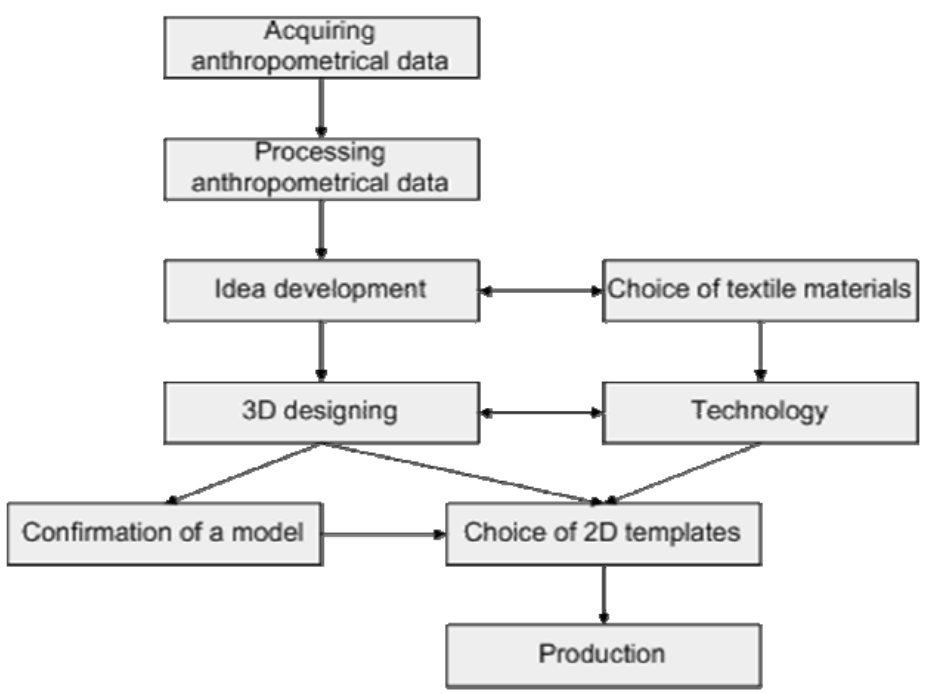

\section{a. Garment}

In this process we can understand the introduction of an expert system. Now the real goal is to get the garment sold on the market, based mostly on fashion, meaning subjective emotion.

Also it is the sale of the garment that contributes to the enhancement of the technologic 3D representations.

\section{b. The fabric}

The fabric behavior simulated in a 3D scene must also contribute to the image weared by the virtual character.

So a lot of works have been done for the representation of the mechanic characteristics of the fabrics.(14) If the fabric is simulated, it should warrant the realistic 3D representation including collision with the mannequin. This realistic topic is not limited to the mechanical computation in the model but also in the composition (simulation of yarn)

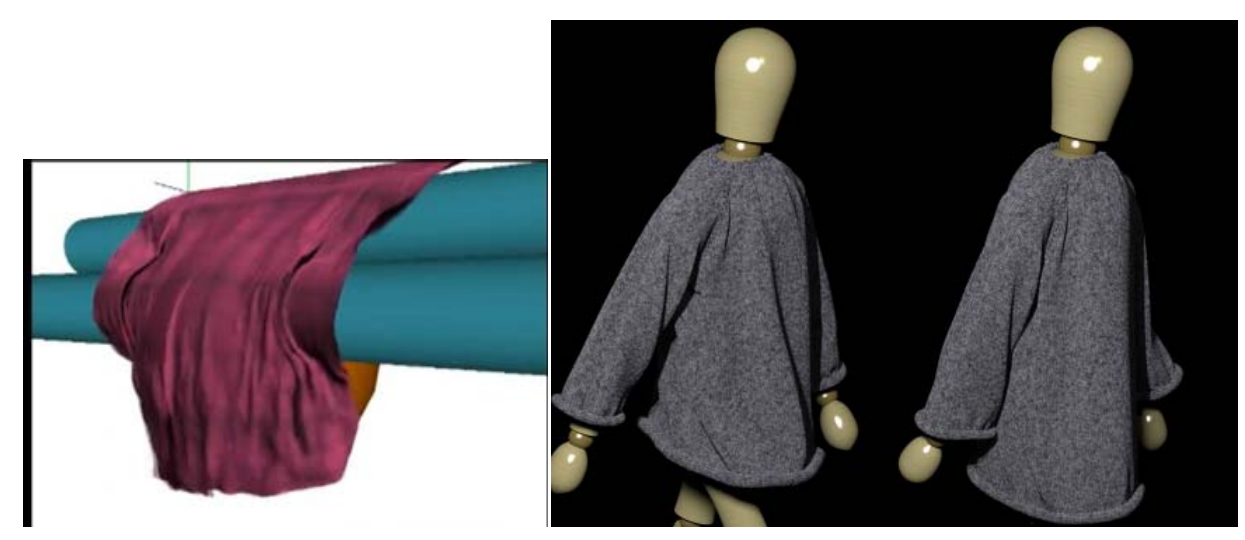




\section{c. Mannequin: which reference?}

Sizes are a production concept. People are not born according to a cluster named "size".

Sizes are an artificial gathering of consumers that allow a segmented production of garments which dimensions are supposed to fit for most of the people that have been statistically gathered into the "size" according to their measurements.

Many size surveys have been launched using body scanners and by the way give a new knowledge of the of the consumers populations...And consequently, give a better garment construction adapted to the consumer's target. This is now the general tendency, build garments adapted to a target population. However in the fashion field, which is different from apparel there is an ideal approach of the style, like a purified representation which is supported by the size zero concept.. The debate concerning this concept is built on the idea that people have to adapt themselves to the garment size, The fitness environment including diets have economical supports. This aspect has social consequences concerning the representation of the "self" in the garment through the sight of the others. (10)

\section{Technical and practical aspects}

\section{a. The wearability of a garment}

Here is the difference between a car and a cloth. Cloth is a second volume (12) used both for comfort an esthetics. Its also a social tool that acts as gap between social and individual environment. The body is the stating point : anatomic references, body built morphology, and the "size" to which the garment style is dedicated, including subjective comfort.(12)

Now the designer and patternmaker have to contribute to there own developments.

\section{b. Confidence and doubt}

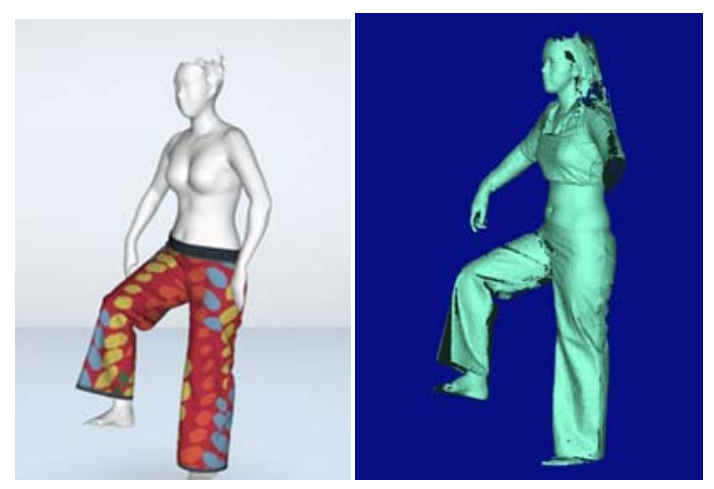

Where is the limit for the expertise field and the vision of the space of the garment, in the future, wearing a human character. Here is the place for the designer skill, developing there process thanks to the 3D representation. The 3D scene displays the tight link between the garment, the effects of the mechanical properties of the fabric that interact with the mannequin.

Designers are today the only experts that have the knowledge, and the only reference to introduce this knowledge into a technical support.

The display with a realistic rendering is a key tool to get a garment fit for the very mannequin who will present the collection in a real catwalk. It is through this display that the fashion will progress because an expert system is not really a tool for innovation and creativity.(13) 


\section{c. Evidences}

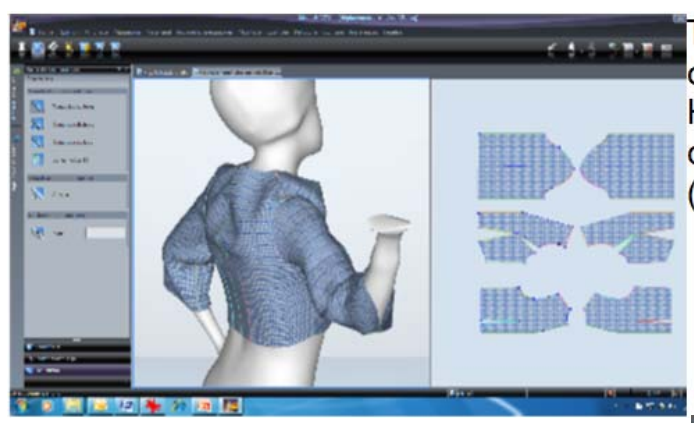

The use of the trilogy in a 3D environment gives evidence of the behavior of a construction (15)

Here the skill operator finds the links between construction, body measurements and fabric mechanics (the trilogy)

In another context, the 2D conception of the cylist garment, built on a close to the body design including fabric elasticity,

The posture induces an elastic reaction that will be analysed and compensated by a front shape different.

The designers have the right profile to integer the different parameters involved in the correction of such a situation.
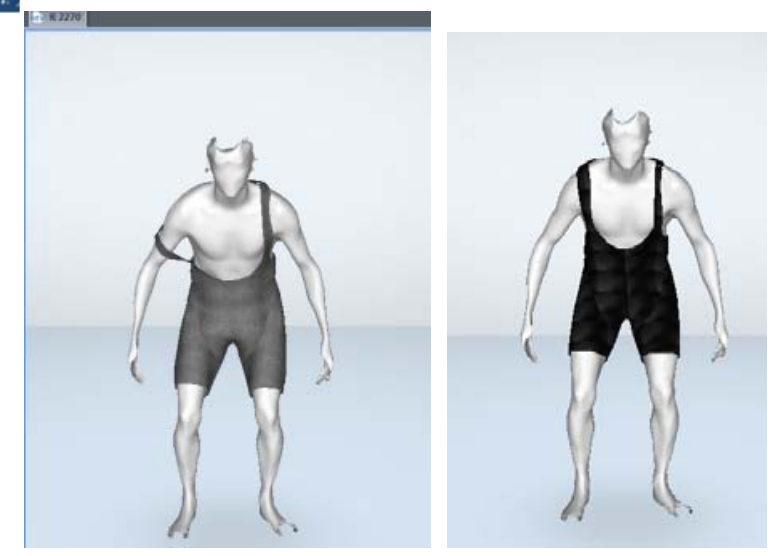

The screen becomes a place where exchanges may occur between skill teachers but also between designers and patternmakers. All situations are not introduced in expert systems as rules as creation is not a determinist process

\section{Discussion}

These profiles, supposed to be outperformed by these technical realization, become now the most representative users because of the discover of new tools supporting their creative activities

\section{The tendency to go back to hand sewn}

There is a real value added by screen display of $3 \mathrm{D}$ trilogy computation. This added value come from the ability to wear a scanned clone of a real person instead of virtual artists The 3D measurements are a warranty for approaching a good fitting. " the use of the 3D virtual try-on onto the true virtual bodies has an added value for the understanding of the interaction between body and garment. In an industrial context, the skilled becomes an efficient actor that can't be reduced to a minimum tool required to enhance creativity. This $3 \mathrm{D}$ environment even complex let a wide part for the pattern maker job

In this industrial context, the heart of the garment knowledge comes back like a hand sewn jacket.

\section{Conclusion}

In other fields thes new 3D technologies follow and invite the return of the original jobs At the moment when we are living a worldwide crisis, which is economics, financial social, and ecologic, the arts skills craft industry are a serious track among others like expert systems, for trying a better economical context. This return is not really speculative, neither virtual even is applied in a virtual environment. This return is built on high skill and knowledge with high added value.(1) 


\section{References}

(1) Télérama 3261- 11 juillet 2012 le cousu main

(2) Conference proceedings advanced apparel "the cutting room of the future" October 25-26 1977 Georgia institute of technology Atlanta Georgia.

(3) Maggie Stott, Pattern Cutting for Clothing Using CAD: How to Use Lectra Modaris Pattern Cutting Software ,Woodhead Publishing Ltd (31 October 2012)

(4) Nadia Magnenat-Thalmann Virtual Humans at MIRALab MIRALab (Université de Genève) MIRLab, Centre universitaire d'informatique

(5) Xavier Provot. Animation Réaliste de Vêtements. Thèse de doctorat, Synthim - INRIA, France, December 1997

(6) Hartmut Rödel, Andrea Schenk, Claudia Herzberg, Sybille Krzywinski, Links between design, pattern development and fabric behaviors for clothes and technical textiles International Journal of Clothing Science and Technology, Volume 13 issue $3 / 4$ (pp. 217 - 227)

(7) http://poser.smithmicro.com/

(8) Y. Cui, D. Stricker 3D body scanning with one Kinect. Proceedings of the International Conference on 3D Body Scanning Technologies Lugano, Switzerland, 19-20 October 2010 Editor and Organizer Hometrica Consulting - Dr. Nicola D’Apuzzo Switzerland

(9) http://onderwijsinbewegingmetkinect.wordpress.com/about/

(10) http://en.wikipedia.org/wiki/Size zero

(11) Expert Systems Vol 29 (5 Issues in 2012) Edited by: Jon G. Hall

(12) Michel Lamy, Les enveloppes écologiques de l'homme, Presses universitaires de Bordeaux, 1993.

(13) Ausma viěumsone and inga dāboliha, computer aided garment designing, bul. inst. polit. iasi, t. Ivi (Ix), f. 4, 2010

(14) Virtual Clothing: Theory and Practice by P. Volino and N. Magnenat-Thalmann, Springer, 2000, ISBN 3-540-67600-7

(15) Jean-Marc SURVILLE, Posture, 3D Real Body, Virtual Try-On: Toward fashion. 2nd International Conference on 3D Body Scanning Technologies, Lugano, Switzerland, 25-26 October 2011 